\title{
The study of College English teaching Internet plus "mode of thinking
}

\author{
Kuikui Zhang ${ }^{1, a}$ \\ ${ }^{1}$ School of Foreign Languages \& International Studies, Shandong Yingcai University, Shandong, 2 \\ 50104, China \\ aemail happykuikui@163.com
}

Keywords: Internet plus the teaching efficiency of English Teaching

Abstract.With the development of economic globalization, more closely between countries, English as an international language in international communication plays a very important role, therefore, as students learn English well is very necessary. The development of the Internet has brought a new mode for English teaching, and with the recent "Internet plus" concept put forward, as a way of thinking about the university teaching has brought new direction and ideas. "Internet plus" means to the Internet as a medium, promote the transformation of traditional industries, the traditional industry and modern information communication technology is connected, it can bring additional development for traditional industries, so as to produce economic benefits.

\section{Introduction}

At present, with the rapid development of our economy, and promote the development of the international community in global economic development and the more obvious, English as an international language can help us to go out, in addition, in our country "The Belt and Road" initiative, strengthen international cultural and economic exchanges need more international the help of language, therefore, out of the new requirements for College English education. But now, China's College English education, widespread English teaching emphasizes writing while ignoring its use, pay more attention to English reading and writing ability and not pay attention to listening and speaking ability, especially in the test, it is demonstrated how readers to the world trend. Therefore, this requires college English teaching can change the traditional teaching model, in the "Internet plus" the trend of the reform of higher education of tradition.[1]

\section{2. "Internet plus" mode of thinking in English Teaching in Colleges and universities}

At present, most of the higher education in our country still adopt the former teacher centered teaching mode. In this teaching mode, the teacher is teaching, students are learning under the guidance of teachers, the form is mainly through a teacher in the classroom to the students of knowledge, and most of them belong to the didactic teaching, with more restrictions on students' learning, and this teaching mode has a relatively closed, is not conducive to the students to communicate. In addition, teachers in the teaching process are mainly based on the contents of textbooks, the selection is relatively old, the relative content of lack of novelty, this teaching mode can help students lay a good foundation but not conducive to the cultivation of students' English communication ability and application ability. Moreover, classroom teaching because of the teaching content of one sightedness and monotonicity, knowledge enables the students to contact in the process of teaching is relatively narrow, so the current scope of international exchange a wide background in teaching the teaching quality and effect is relatively poor.[2]

The traditional teaching mode of college teachers can teach a lot of knowledge in a short period of time, for college students, so that classroom time is difficult to accept and absorb a lot of knowledge, but also in the class is not only difficult to sort out these knowledge points, also affect the absorption of students. Also, in traditional teaching, teachers often pay more attention to their own teaching and ignore the students' foundation and master the knowledge, therefore, only for some good or most of the students in the class, the number of college enrollment and other reality, most of the colleges in the class of about 50 people, which is high requirements for classroom teaching, but the teaching of 
English is often not up to the requirements of teaching, especially in English Teaching for non English Majors in the English curriculum as a public course even less attention, resulting in teaching investigation usually appear the formality of the investigation, for most students in the exam before reading or are ready to assault you can through the exam. Moreover, with the increasing popularity of mobile phones, there has been a large number of "low family" in the classroom. This behavior directly influences the quality of students' lectures and the quality of teaching.[3]

Therefore, in view of the above problems, it is necessary to introduce the teaching of College English "Internet plus" thinking, the traditional college English teaching and the combination of modern Internet, reform the traditional teaching model, the College English teaching can conform to the current trend of social development continuously, according to the society of University graduation requirements and continuously improve the quality of the level of college students, cultivate their comprehensive ability and practical ability of english. From this fact we need to be able to "Internet plus" thinking teaching, exploring the effect of the Internet as a platform and media and traditional English teaching produced, and new forms of Mu class using the continuous and micro class teaching mode and thinking, the innovation of teaching content, the enthusiasm of the time to improve the students' English learning, thus improving the quality of teaching.

\section{Build Internet plus College English teaching mode}

\subsection{Diversified development of teaching mode}

In the existing teaching in Colleges and universities, usually with teachers as the center of the class, in the teaching of the content of the textbook is the main knowledge, usually pay more attention to the common knowledge, while ignoring the development of students' personality and their own characteristics. In this way, teachers in the teaching process of knowledge for students and not fully accepted and absorbed, and for some foundation are not very good for students, the learning will be more difficult, it will affect the overall quality of teaching. If the teacher taught English knowledge as a resource view, the students in the classroom cannot fully absorb the teachers teach knowledge is a waste of resources, not only for students, it is a waste of their achievements for teachers. This requires us to constantly change our thinking and introduce Internet thinking into college English teaching. We should try to change English teaching from commonness to individuality.[4]

At present, with the development of science and technology, the scope of big data in our life continues to expand. Big data analysis in our shopping and browsing habits, recommended for our interest in a period of time links and product recommendation, and relevant product ads will appear in our computer search engine interface, which fully shows the application of big data in our life, and through the form of advertising to us to demonstrate its function. This provides a new way for College English teaching, teachers can analyze the characteristics of each student and learning mainly according to the operating rules of big data, and based on the analytical results obtained on and according to the needs of students of knowledge push and guide. Therefore, through the use of big data, is conducive to the building of "Internet plus College English teaching" mode. Diversified teaching mode is mainly manifested in two aspects, the first is the teacher in the classroom by explaining the textbook knowledge to explain to students the most basic learning method and basic knowledge, and the common problems in the learning process of students to solve the second is to solve the problem of students through modern personality the communication technology of the Internet and big data, according to the different needs of each student to push knowledge, it can help the students get their different needs for knowledge, and constantly develop students' independent learning ability, so as to improve the students' comprehensive ability and high quality of English teaching.

\subsection{Improve the convenience of English Learning Applications}

English as a language, its characteristics mainly show that learners need to cultivate language sense and learning atmosphere in a certain context. In addition, in English, in the process of learning, it is necessary in order to keep repeating and practicing. In the course of continuous practice, memory and learning can be utilized to ensure ensure that students master what they have learned in the 
process of learning. However, in the current English learning in college, most of the students is the main use of the time in the class of knowledge learning, classroom unexpected time as part of a professional lessons, one part is used to learn other knowledge about English learning time is relatively small, it is less time for learning english. In addition, because English textbooks are relatively large, it is not particularly convenient for students to learn English. Therefore, it is needed for the Internet to be an English learning platform. Through modern communication technology and the use of English learning software, guide students to review English in the fragmented time, recite words and so on. At present, with the progress of MOOC, Ted, Coursera and other electronic courses and websites, it is possible and convenient for students to contact different types of learning methods. With the increasing functionality of smart phones and the soaring popularity of mobile phones, it makes it easier for students to use the Internet to learn.

In the "Internet plus College English teaching mode, can give full play to the guiding role of teachers, can be in the classroom for students to show the latest achievements in scientific research and knowledge, after guiding the students to complete the basic knowledge accumulation, through Internet technology continues to push the knowledge points, allowing students to summarize and review of knowledge in class, and the use of spare time to learning and memory, so that it can meet the Ebbinghaus memory curve, so that students can achieve the purpose of knowledge in repeated memory.[5]

\subsection{To improve the openness of College English Teaching}

As a carrier of culture, language is a non-material manifestation of the development of history and culture in different countries. Therefore, language learning cannot be simply learned by rote. Learning a language should be done on the basis of mastering the basic knowledge. Once language learning from the cultural atmosphere is very difficult to achieve proficiency level, so the College English education should pay attention to English learning. Language learning on the learning culture can achieve a multiplier effect. At present, in our college English teaching, although the teachers in the teaching process will involve the corresponding culture, but its content is based mainly on the subjective knowledge of teachers, often with strong limitations. Moreover, in the limited classroom time, it is sometimes difficult to speak of the knowledge of culture thoroughly. Therefore, through the Internet, students can be susceptible to the culture and history of more English speaking countries, which will help them learn english.

In the "Internet plus" mode of teaching, the school can be through cooperation and exchange projects with foreign universities, the students to communicate through the network, not only increased the enthusiasm of students to learn English, but also can lead to the exchange of ideas, improve teaching openness, introducing more cultural elements. At the same time, in the process of cultural exchange, we should pay attention to resist unhealthy cultural erosion and improving students' self judgment ability. [6]. Secondly, universities can also cooperate with domestic colleges and universities, especially the two or three line of the city's colleges and universities, we should try to improve the openness of teaching through the Internet and other media, let students to teachers of different levels. In particular, many colleges and universities now offer different forms of online courses that can help them find out how come into contact with different kinds of knowledge and ways of teaching so as to improve their learning level.

Therefore, in the Internet era, through the Internet thinking of teaching resources integration, and in teaching, in fact, can build a good, open teaching model, and constantly improve the quality of teaching.

\section{4."Internet plus College English teaching notes}

\subsection{Pay attention to the innovation of the way}

"Internet plus" as a way of thinking in the teaching of College English in the application and cannot simply integrate resources, or information on the Internet will be introduced into the teaching, so it is easy to cause the confusion of knowledge learning. For example, some schools simply to guide students to network knowledge learning, but learning rules of learning content and unified test, this 
method would result in the traditional teaching mode of modern information teaching for wearing the coat, only the existing network learning resources for simple processing, not in accordance with the "substantive requirements Internet plus College English teaching".

Therefore, in the construction of "Internet plus College English teaching mode, teachers should avoid simple resource overlay, but to innovate in teaching on the basis of the original. On the one hand to carry out teaching according to the common characteristics of students, increase students' learning interest and enthusiasm, to create a good learning platform to understand the basis of the students, provide a good learning experience for students, feel the Internet brings different teaching modes. On the other hand, the need to introduce large data based on the Internet, according to the characteristics of different students to push the problem analysis and knowledge points, and according to the data, the corresponding learning goals for students to develop, and every day the study plan, so the more can promote the improvement of students' learning.[7]

4.2Pay attention to both form and content

"Internet plus College English Teaching" as a new model of College English teaching, the form is novel in terms of teaching, is a new application of science and technology in the field of education, but note that in the "Internet plus College English teaching mode, the teaching content is the core. This model not only needs to innovate from the technology and the form, but also needs to change the teaching content unceasingly, satisfies the society at the University talented person's demand. On the one hand, to avoid the name of "Internet plus" name, but still followed the traditional teaching mode, on the other hand, also need to guide students to consciously choose learning content in the learning process, not only need to meet the diversified development of the society, also need to pay attention to meet the needs of the construction of socialist culture in our country, to resist adverse foreign culture erosion. In addition, in the process of learning, we should also pay attention to the use of the learning content and the times, which are more conducive to students in after graduation can quickly integrate into the social environment.

\subsection{Constructing the systematicness of English Teaching}

English, as an imperative language, is closely and systematically. Therefore, in the "Internet plus College English teaching model should focus on the system of learning. In the process of learning not only need to guide and encourage students to make full use of spare time for the knowledge of memory and learning in the "Internet plus" learning, also need through classroom teaching mode to help students build a complete knowledge system, promote the comprehensive development of English thinking. This requires teachers to effectively integrate the teaching resources in the course of teaching and make a judicious division, so as to ensure the quality of teaching in the process of teaching.[8]

\section{References}

[1]Kirk R. A STUDY OF THE USE OF A PRIVATE CHAT ROOM TO INCREASE REFLECTIVE THINKING IN PRE-SERVICE TEACHERS[J]. Journal of Macroeconomics, 2000, 11(2):269-280.

[2]Liu D. Making Grammar Instruction More Empowering: An Exploratory Case Study of Corpus Use in the Learning/Teaching of Grammar[J]. Research in the Teaching of English, 2011, 45(4):353-377.

[3]Robinson E R. Study of the Undergraduate Preparation of Potential Teachers of Secondary-School English in Selected New England Colleges[J]. The Journal of Educational Research, 1955, 48(9):641-647.

[4]Min, Dai. The Study of English teaching mode based on information platform in higher vocational education[J]. International Journal of Technology Management, 2014, 63(3):49-51.

[5]Paul H. Smith. Troops to Teaching: lessons from English teaching assistants' experiences of foundation degree study[J]. Journal of Education for Teaching, 2012, 38(5):525-537. 
[6]Suprapto A. THE IMPLEMENTATION OF LESSON PLANS IN TEACHING PRACTICES OF SIXTH SEMESTERSTUDENTS OF ENGLISH EDUCATION DEPARTMENT OF MURIA KUDUS UNIVERSITY IN MICRO TEACHING CLASS IN THE ACADEMIC YEAR 2012/2013[J]. Journal of Fish Biology, 2013, 75(10):2862 - 2867.

[7]Nannan, Zidan. Study on the Practice Teaching Quality Guarantee and Monitoring System of English Program in Local Colleges and Universities[J]. International Journal of Technology Management, 2013:76-78.

[8]Martínez-Gómez M, Sierra J M C, Jabaloyes J, et al. A multivariate method for analyzing and improving the use of student evaluation of teaching questionnaires: a case study[J]. Quality \& Quantity, 2011, 45(6):1415-1427. 